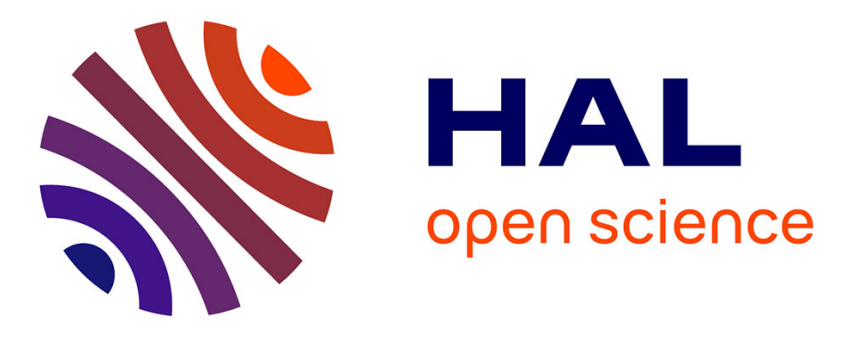

\title{
Impurities enhance caking in lactose powder
}

Mélanie Carpin, H. Bertelsen, A. Dalberg, Claire Roiland, J. Risbo, Pierre

Schuck, Romain Jeantet

\section{To cite this version:}

Mélanie Carpin, H. Bertelsen, A. Dalberg, Claire Roiland, J. Risbo, et al.. Impurities enhance caking in lactose powder. Journal of Food Engineering, 2017, 198, pp.91-97. 10.1016/j.jfoodeng.2016.11.013 . hal-01408010

\section{HAL Id: hal-01408010 https://hal.science/hal-01408010}

Submitted on 3 Apr 2017

HAL is a multi-disciplinary open access archive for the deposit and dissemination of scientific research documents, whether they are published or not. The documents may come from teaching and research institutions in France or abroad, or from public or private research centers.
L'archive ouverte pluridisciplinaire HAL, est destinée au dépôt et à la diffusion de documents scientifiques de niveau recherche, publiés ou non, émanant des établissements d'enseignement et de recherche français ou étrangers, des laboratoires publics ou privés. 


\section{Accepted Manuscript}

Impurities enhance caking in lactose powder

M. Carpin, H. Bertelsen, A. Dalberg, C. Roiland, J. Risbo, P. Schuck, R. Jeantet

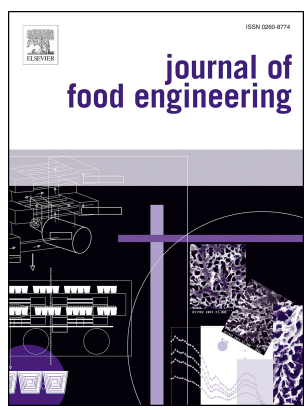

PII: S0260-8774(16)30420-4

DOI: $\quad$ 10.1016/j.jfoodeng.2016.11.013

Reference: JFOE 8718

To appear in: Journal of Food Engineering

Received Date: 30 August 2016

Revised Date: 13 October 2016

Accepted Date: 18 November 2016

Please cite this article as: Carpin, M., Bertelsen, H., Dalberg, A., Roiland, C., Risbo, J., Schuck, P., Jeantet, R., Impurities enhance caking in lactose powder, Journal of Food Engineering (2016), doi: 10.1016/j.jfoodeng.2016.11.013.

This is a PDF file of an unedited manuscript that has been accepted for publication. As a service to our customers we are providing this early version of the manuscript. The manuscript will undergo copyediting, typesetting, and review of the resulting proof before it is published in its final form. Please note that during the production process errors may be discovered which could affect the content, and all legal disclaimers that apply to the journal pertain. 


\section{Impurities enhance caking in lactose powder}

2 M. Carpin ${ }^{1,2,4}$, H. Bertelsen ${ }^{2}$, A. Dalberg ${ }^{2}$, C. Roiland ${ }^{3}$, J. Risbo ${ }^{4}, \underline{\text { P. Schuck }}{ }^{1}$, R. Jeantet ${ }^{1}$

$3{ }^{1}$ UMR 1253, Science and Technology of Milk and Eggs, Inra-Agrocampus Ouest, 35042

4 Rennes cedex, France

$5 \quad{ }^{2}$ Arla Foods Ingredients Group P/S, 6920 Videbæk, Denmark

$6{ }^{3}$ University of Rennes 1, UMR CNRS 6226, Campus de Beaulieu, Rennes, France

$7 \quad{ }^{4}$ Department of Food Science, University of Copenhagen, 1958 Frederiksberg C, Denmark

8 melanie.carpin@inra.fr

9 hans.bertelsen@arlafoods.com

10 anders.dalberg@arlafoods.com

11 claire.roiland@univ-rennes1.fr

12 jri@food.ku.dk

13 pierre.schuck@inra.fr

14 romain.jeantet@agrocampus-ouest.fr

15 Abstract:

16 Caking of lactose and other dry ingredients is a common problem in the dairy and food

17 industries. The lactose production process includes different purification steps, depending on

18 the type of lactose produced. The aim of this study was therefore to investigate how the

19 remaining impurities (i.e. non-lactose components) affect the caking tendency of the final

20 powder. The results from a combination of different methods, including dynamic vapor sorption,

21 characterization of the physicochemical composition and assessment of caking with a ring

22 shear tester, suggested humidity caking. Larger amounts of impurities in the lactose powder

23 resulted in enhanced moisture sorption and greater caking tendency. These findings emphasize

24 the importance of controlling the washing and purification steps throughout the production

25 process in order to limit caking in the final product.

26 Keywords:

27 Caking, lactose, impurities, amorphous, moisture sorption, ring shear tester 
29 As a consequence of trade globalization and significant advances in drying and powder handling

30 technology, the volume of food ingredients produced in powder form has dramatically increased

31 in the past decade. Indeed, as dry ingredients have better storage stability and are easier to

32 transport, a major part of the recent investments in the dairy sector has been focused on dry

33 products (International Dairy Federation, 2015). In particular, whey, which was traditionally

34 considered as waste, has gained considerable attention, and its different constituents (whey

35 proteins, lactose, lactoferrin, milk salts, etc.) are now separated and sold as high value products

36 in the dry state. The range of applications for whey-derived dry ingredients has thus expanded

37 considerably.

38 Among the whey-derived ingredients, lactose is used in various food and pharmaceutical

39 applications. For example, lactose powder is the main ingredient of infant formulae and provides

40 an important source of carbohydrates to match the composition of human milk. Lactose can be

41 found in different forms, but the most common and stable form is crystallized $\alpha$-lactose

42 monohydrate. $\alpha$-lactose monohydrate is produced industrially by evaporation of whey followed

43 by slow cooling in a crystallization tank. Typically, the harvested crystals are then washed and

44 dried in a fluidised bed dryer. Different purification steps can make the process more complex,

45 depending on the type of lactose produced. For example, calcium and phosphate are usually

46 removed prior to evaporation in order to increase the running time of the evaporators and reduce

47 fouling. The lactose production process has been described in greater detail by Hourigan et al.

48 (2013).

49 The handling and storage of lactose and other dry food products can be complicated by a

50 problem that is well known in the food industry, i.e. the unwanted agglomeration of powder

51 particles observed as lumps of various sizes and hardness. This process, known as caking,

52 results in non-conform products and significant economic loss. Although a-lactose monohydrate

53 is generally considered to be a stable product, caking of lactose is a major problem in the dairy

54 industry. The three most relevant caking mechanisms in food powders have recently been

55 reviewed (Carpin et al., 2016). Amorphous caking is the main mechanism in amorphous

56 powders whereby a temperature increase above the glass transition temperature $(\mathrm{Tg})$ of the 
at relatively high relative humidity $(\mathrm{RH})$ can lower the $\mathrm{Tg}$ and initiate amorphous caking.

59 Humidity is also a crucial factor in the second caking mechanism, called humidity caking. Water

60 molecules are adsorbed on the surface of the particles and liquid bridges can be formed by

61 capillary condensation. If the $\mathrm{RH}$ increases above the deliquescence relative humidity (DRH) of

62 the material, the solid can dissolve in the surrounding water layer. A subsequent decrease in $\mathrm{RH}$

63 results in solid bridges and thus stronger links between particles. Finally, the third mechanism,

64 mechanical caking, is an aggravating factor rather than a caking mechanism in itself. Mechanical

65 pressure on a powder bed brings the particles closer to each other, thereby increasing the

66 interactions between particles and the number of contact points. Mechanical caking therefore

67 worsens any caking tendency due to humidity or the presence of amorphous material.

68 In view of the above three mechanisms, it is obvious that caking can be influenced by several

69 parameters such as water content, particle size and shape, amorphous content, etc. Several

70 studies have investigated how these factors affect caking of $\alpha$-lactose monohydrate. Listiohadi et

71 al. (2008, 2005a, 2005b) focused on the role of the different lactose polymorphs, amorphous

72 lactose and the milling procedure. Bronlund and Paterson (2004) examined the effects of particle

73 size and temperature on the moisture sorption characteristics of lactose powder and

74 temperature-induced moisture migration in a bag of lactose (Paterson and Bronlund, 2009). As

75 humidity has a crucial role in both amorphous and humidity caking, any impurity that can

76 enhance lactose hygroscopicity, such as peptides and minerals, can be detrimental. This

77 parameter has not been investigated to date. The aim of this study was therefore to characterize

78 the effects of impurities on lactose caking.

79 2. Materials and methods

80 2.1. Production of lactose powders on a pilot scale

81 Decalcified and decolored ultrafiltered (UF) whey permeate was obtained from Arla Foods

82 Ingredients, Viby J, Denmark. The solids content was raised to $60 \%$ in a Centritherm CT2

83 evaporator (Flavourtech, Griffith, Australia). The concentrate was cooled in a tank from $79{ }^{\circ} \mathrm{C}$ to

$8411^{\circ} \mathrm{C}$ in about 18 hours for lactose crystallization purposes. For the washing step, a Lemitec 
five lactose powders with different washing grades. The slurry was first run through the decanter

87 once without water for a pre-wash (Wash 0). The prewashed slurry was then mixed with water at

88 different water / lactose slurry (w/w) ratios: 1/3 (Wash 0.3), 1/2 (Wash 0.5), 1/1 (Wash 1) and 2/1

89 (Wash 2). The different washing grades of slurry were run through the decanter once more, and

90 then dried on an Anhydro SFD 47 spin flash dryer (SPX Flow Technology, Søborg, Denmark)

91 with an inlet temperature of $105^{\circ} \mathrm{C}$ and an outlet t emperature of $82-87^{\circ} \mathrm{C}$. Finally the powders

92 were packaged in two layers of plastic bags and a Kraft paper bag before transportation to the

93 analysis laboratory where they were poured into airtight plastic containers of various sizes to

94 minimize the headspace. The powders were stored at $20^{\circ} \mathrm{C}$ before analysis.

95 Pharmaceutical grade lactose (Lactochem ® Crystals, batch number 663108) was purchased

96 from DFE pharma (Goch, Germany) for comparison with the experimental lactose powders

97 produced at different washing grades. Pharmaceutical grade lactose is produced industrially

98 from edible grade lactose by re-dissolving the lactose in clean water followed by additional

99 purification steps (Paterson, 2009). It is therefore the most pure lactose available on the market.

100 Pharmaceutical grade lactose was mixed with distilled water to make a $15 \%(\mathrm{w} / \mathrm{w})$ lactose

101 solution which was left to stand at $40{ }^{\circ} \mathrm{C}$ for one h our. The solution was then cooled to $20^{\circ} \mathrm{C}$ and

102 spray dried on a pilot-scale spray dryer (GEA Niro A/S, Mobile Minor Dryer (MMD), Soeborg,

103 Denmark) to obtain amorphous lactose. The inlet and outlet air temperatures were $200{ }^{\circ} \mathrm{C}$ and

$10490^{\circ} \mathrm{C}$, respectively, and the feed flow rate was $40 \mathrm{~mL} \cdot \mathrm{min}^{-1}$.

105 2.2. Chemical composition

106 Protein, moisture and ash content were determined according to the methods described by

107 Schuck et al. (2012). Total nitrogen content determined by Kjeldahl with a 6.38 conversion factor

108 will be designated as protein content. Given the filtration steps in the lactose process, it is

109 however unlikely that proteins remain in the final powder. Therefore, impurities formally

110 expressed as protein may more likely be smaller nitrogen containing components such as

111 peptides and amino-acids. Analysis of moisture and ash content was carried out in triplicate and

112 the protein content was determined in duplicate. The lactose content was then calculated by 
measured by inductively coupled plasma optical emission spectrometry (ICP-OES) on an

115 Optima 2000 DV (PerkinEImer, Waltham, Massachusetts, USA). Chloride was determined by

116 potentiometry. All minerals were analyzed in duplicate.

117 2.3. Sieving and measurement of particle size

118 The lactose powders of different washing grades were sieved to separate $80,160,250,355$ and

$119500 \mu \mathrm{m}$ fractions. The particle size distribution of the powders was measured by laser light

120 scattering using a Malvern Mastersizer 2000 equipped with a Scirocco 2000 dry dispersion unit

121 (Malvern Instruments, Worchestershire, UK).

122 2.4. Moisture sorption measurements

123 Sorption isotherms of powders were obtained with a Dynamic Vapor Sorption (DVS) Advantage

124 (Surface Measurement Systems Ltd., London, UK) equipped with a Cahn microbalance. The 125 experiments were carried out in duplicate at a constant temperature $\left(25^{\circ} \mathrm{C}\right)$ using a nitrogen 126 flow rate of 200 standard $\mathrm{cm}^{3} \cdot \mathrm{min}^{-1}$. Approximately $40 \mathrm{mg}$ of powder was subjected to ramping 127 of $\mathrm{RH}$ from $0 \%$ to $95 \%$ in $10 \%-\mathrm{RH}$ steps with water as solvent. Equilibrium was considered to be 128 reached if the rate of change in mass was less than $0.0002 \% \cdot \mathrm{min}^{-1}$.

129 2.5. Particle morphology — scanning electron microscopy (SEM)

130 The surface morphology of the lactose samples was examined using a scanning electron

131 microscope (SEM, JEOL JCM-6000 - NeoScope II, Tokyo, Japan) operating at $15 \mathrm{kV}$. Samples 132 were mounted on an aluminium stub and coated with a thin layer of gold (JEOL JFC-1300 auto 133 fine coater) prior to analysis. The photomicrographs were taken at $\times 1,000$ magnification.

134 2.6. Solid-state Nuclear Magnetic Resonance (NMR)

135 13C NMR spectra were obtained using proton decoupling, magic angle spinning (MAS) and 136 cross polarization (CP). The spectra were recorded on a Bruker Avance I WB $300 \mathrm{MHz}$ 137 (7T) instrument (Bruker, Billerica, USA) at ambient temperature according to the method 138 described by Gustafsson et al. (1998), with the following parameters: spinning rate $5 \mathrm{kHz}$, 
of 3 s. For each spectrum, about 150,000 transients were cumulated with $49 \mathrm{k}$ data points. The

141 spectra were referenced to trimethylsilane (TMS).

\subsection{Quantification of caking}

143 Caking, also known as time consolidation, was measured with a ring shear tester (RST-XS,

144 Schulze-Schüttgutmesstechnik, Wolfenbüttel, Germany). The measurement procedure has been 145 described in detail by Schulze (2008). First the yield locus of each powder was measured for a 146 normal stress at preshear $\sigma_{\text {pre }}$ corresponding to a consolidation stress $\sigma_{\mathrm{c}}$ of around $9.3 \mathrm{kPa}$. This 147 value was chosen to simulate powder consolidation at the bottom of a flexible intermediate bulk 148 container (FIBC), also called a Big Bag. Three points of incipient flow were used to draw the 149 yield locus. Once the initial yield locus was established, the powder was preconditioned using

150 the same $\sigma_{\text {pre }}$ as above and stored at $20{ }^{\circ} \mathrm{C}$ and $60 \% \mathrm{RH}$ for four $\mathrm{d}$ ays. A temperature and 151 humidity data logger was used to check the storage conditions. Loads of $2 \mathrm{~kg}$ (corresponding to 152 a consolidation stress of $9.3 \mathrm{kPa}$ ) were applied to the samples for the duration of storage. After 153 storage the samples were sheared to obtain the time yield locus. From this, the unconfined yield 154 strength $\sigma_{1}$ and the ratio of $\sigma_{c}$ to $\sigma_{1}$, called $f f c$, were identified. By definition, a sample with an $f f c$ 155 lower than 1 was considered to be caked (Jenike, 1964). For each powder except Wash 0.3, the

$156 \mathrm{ffc}$ was measured in triplicate. As the amount of Wash 0.3 was limited, the analysis could only be 157 performed in duplicate.

158 3. Results and discussion

159 3.1. Chemical composition

160 The results showed, as expected, that the higher the washing grade, the fewer the remaining 161 impurities measured in the final powder (i.e. nitrogen containing components expressed as 162 proteins, free moisture, ash and minerals) (Table 1 and Fig. 1). The remaining ash and protein 163 levels were highly correlated $\left(R^{2}=0.972\right)$. Moreover, ash and protein levels were found to 164 correlate better with moisture measured by loss on drying at $87^{\circ} \mathrm{C}$ for 16 hours $\left(R^{2}=0.995\right.$ and $165 R^{2}=0.972$, respectively) than with moisture measured after drying at $105^{\circ} \mathrm{C}$ for 5 hours $\left(R^{2}=0.709\right.$ 
drying has been criticized for the lack of discrimination between the different types of water,

168 distinguished by the extent of binding with solids (Isengard, 2001). "Free" and "bound" water can

169 indeed be difficult to differentiate, and the results at $105^{\circ} \mathrm{C}$ may overestimate the "free" water

170 content of the samples.

171 The amounts of all minerals decreased with a higher degree of washing, with the exception of

172 calcium (Fig. 1). The decalcification and subsequent separation steps applied to the UF

173 permeate reduced the initial calcium and phosphorus content (Hourigan et al., 2013). Thus the

174 starting material for the trial already had low calcium and phosphorus content from the

175 beginning. Fig. 1 shows that it was not possible to reduce the calcium content much further by

176 washing the lactose crystals. This suggests that, as mentioned by Guu and Zall (1992), most of

177 the remaining calcium formed strong complexes with lactose. Interestingly, phosphate did not

178 follow the same trend as calcium. Guu and Zall (1991) reported that calcium phosphate

179 precipitates may act as nuclei facilitating lactose crystallization. It was therefore expected that

180 calcium phosphate could be trapped inside the crystals, thereby preventing it from being washed

181 away. This was however not observed in the present study.

182 Using a basic mass balance with simple assumptions, the expected amount of impurities in the

183 different washing grades after decantation was calculated from the amount measured in Wash 0.

184 The water content in the decanter output was considered the same for all washing grades (i.e.

$18510 \%$ ) and it was assumed that no lactose was dissolved during the decantation process. The 186 calculated levels of protein and ash were in general lower than the measured amounts (data not 187 shown). The inclusion of droplets of mother liquor inside the crystals, as suggested by

188 Mathlouthi and Rogé (2003) for sucrose, could explain the limited effect of washing.

189 3.2. Moisture sorption

190 Sieving the powders led to standardization of particle size distribution (Fig. 2). Indeed it has 191 been shown that particle size can have a significant effect on moisture sorption (Stoklosa et al., 192 2012). 
size fraction $(160<x<250 \mu \mathrm{m})$, the sorption of the unwashed powder (Wash 0$)$ was dramatically

195 enhanced from $30 \% \mathrm{RH}$ and the final sorption was almost ten times higher than the most

196 washed powders (Wash 1 and Wash 2). Crystalline lactose is characterized by a very low

197 hygroscopicity, with a deliquescence relative humidity (DRH) value of 95\% (Salameh et al.,

198 2006). However, Tereshchenko (2015) reported that, for a water soluble crystalline solid,

199 moisture sorption below the $\mathrm{DRH}$ was due to impurities. Enhanced sorption and reduced $\mathrm{DRH}$

200 due to the presence of low levels of impurities have also been reported in a model deliquescent

201 pharmaceutical salt, in agreement with our results (Guerrieri et al., 2007). The sorption behavior

202 of the different lactose powders is thus likely to originate from differences in impurity contents

203 (Table 1). This was further evidenced by a comparison with pharmaceutical grade lactose. The

204 latter was found to contain about 20 times less ash and proteins than the most washed powder

205 produced during the pilot trial (Table 1). The difference in moisture sorption behavior between

206 Wash 2 and the pharmaceutical grade powder was very clear: indeed, Wash 2 powder adsorbed

207 almost 10 times more moisture than pharmaceutical grade lactose above $50 \%$ RH (Fig. 4).

208 As moisture sorption occurs primarily on the surface of crystals, a comparison of the surface of 209 the different washing grade lactose powders was undertaken by scanning electron microscopy 210 (Fig. 5). All samples from the pilot trial (Fig. 5A-D) presented a rough surface. Wash 0 powder 211 had many pores (Fig. 5A), which would provide greater possibilities for capillary condensation 212 and could therefore partly explain the enhanced moisture sorption previously reported (Fig. 3).

213 Compared to pharmaceutical grade lactose, which presented a smooth surface (Fig. 5E), Wash

$2140.5,1$ and 2 powders had significant amounts of fines agglomerated on the surface of their large 215 tomahawk crystals (Fig. 5B-D). Mathlouthi and Rogé (2003) showed that the presence of fines in 216 sucrose crystals enhanced moisture sorption and that the greater the number of fine particles, 217 the closer the sorption behavior of the sample to that of the amorphous state. Their findings are 218 consistent with the moisture sorption isotherms obtained in this study, showing less sorption for 219 pharmaceutical grade lactose (Fig. 4).

220 Moreover, a higher concentration of impurities on the surface of the crystals would probably lead 221 to enhanced sorption behavior. On the other hand, impurities trapped inside the crystals are not 
identify which impurities (nature, concentration) are present on the surface of the particles.

\subsection{Role of amorphous material}

225 One particular kind of impurity is amorphous material, which is well known for its high hygroscopicity compared to the crystalline counterpart. Amorphous lactose can be formed on the

227 surface of lactose particles during rapid drying and milling (Vollenbroek et al., 2010). As the

228 samples were dried in a spin flash dryer in the present study, the possibility of formation of 229 amorphous material due to rapid drying cannot be excluded. The impurities remaining after the 230 washing process (e.g. minerals and protein fractions) were likely to retain some mother liquor 231 which could turn into amorphous lactose upon drying. The presence of increasing, yet very low, 232 amounts of amorphous lactose at lower washing grades could thus be another explanation for 233 the enhanced hygroscopicity of the corresponding powders.

234 However, no recrystallization event was observed in the moisture sorption curves, contrary to 235 previously reported sorption isotherms of predominantly crystalline materials containing some 236 amorphous content (Sheokand et al., 2014). For example, a weight increase and subsequent 237 decrease due to amorphous lactose absorbing moisture and crystallizing has been reported in 238 samples containing between 0.125 and 0.5 w/w \% amorphous material (Buckton and Darcy, 239 1995). However, the presence of amorphous material in our samples cannot be ruled out from 240 the sorption isotherms. Residual amorphous lactose might be present at lower levels than those 241 studied by Buckton and Darcy (1995). Moreover, Buckton and Darcy (1995) used physical mixes

242 of spray-dried lactose and $\alpha$-lactose monohydrate in their study, which can facilitate the 243 crystallization event compared to a situation where the amorphous material is in close contact 244 with crystalline portions on the same particle.

245 The samples with different washing grades were therefore analyzed by solid-state NMR. A 246 detection limit of $0.5 \%$ amorphous lactose has been reported for this technique (Gustafsson et 247 al., 1998), which is among the lowest levels for the detection of amorphous material in 248 predominantly crystalline materials (Giron et al., 2007). No disorder indicating amorphous 
amorphous material was present in the samples, the amorphous content was probably below

$2510.5 \%$. However, the analysis of very low levels of amorphous material is always challenging in

252 terms of sample storage and sampling. Indeed, amorphous material can crystallize during

253 storage before analysis, thus preventing its identification.

254 3.4. Caking tendency

255 For the different particle size distributions investigated, the unwashed powder was characterized

256 by a poorer flowability and hence a higher tendency to caking than the washed powders (Fig. 7).

257 Moreover, a ffc after storage of $0.6 \pm 0.1$ was obtained for non-sieved Wash 0.3 while non-

258 sieved pharmaceutical grade lactose still flowed easily after the four-day storage. It was not

259 straightforward to discriminate Wash 1 and Wash 2 powders from each other.

260 It is clear from these results that higher levels of impurities lead to greater risk of caking. In the

261 present study, the samples were stored at $20{ }^{\circ} \mathrm{C}$ and $60 \% \mathrm{RH}$ for four days in the ring shear

262 cells before measurement of caking tendency. Amorphous lactose stored at room temperature

$263\left(20-25^{\circ} \mathrm{C}\right)$ has been reported to crystallize at abou t $40 \% \mathrm{RH}$ (Jouppila and Roos, 1994;

264 Thomsen et al., 2005). Amorphous caking was therefore expected to occur if the samples

265 contained amorphous lactose. However, as mentioned in section 3.3., the solid state NMR

266 analysis did not indicate the presence of disordered structures, meaning that the amorphous

267 content of the samples was probably below $0.5 \%$. Thus amorphous caking cannot be considered

268 to be the main mechanism responsible for the caking tendency observed here. In his work on

269 caking of crystalline lactose, Bronlund (1997) also showed that amorphous caking was only

270 marginal for amorphous content below 5\%, and that the major contribution to caking from the

271 amorphous material occurred through moisture sorption.

272 The sorption isotherms of Wash 0, 1, 2 powders and pharmaceutical grade lactose showed that

273 the difference in sorption behavior was important at $60 \%$ and room temperature (Fig. 3 and Fig.

274 4). During the caking experiments, the samples were given time to equilibrate with ambient air at

$27560 \% \mathrm{RH}$. Due to humidity caking, the caking tendency was therefore expected to be enhanced

276 for samples which could adsorb more moisture. This was confirmed by the flowability results 
Wash 1 was found to adsorb twice as much moisture as Wash 2 at $60 \% \mathrm{RH}$ according to the

279 DVS measurements. The difference in the impurity levels and thus moisture sorption between

280 these two powders was probably too small for the ring shear tester to detect a difference

281 between the caking tendencies of the two powders.

282 As humidity caking could be evidenced by the caking measurements with the ring shear tester,

283 the repeatability of the measurement was considered acceptable. In order to discriminate

284 between samples with similar sorption behaviors (such as Wash 1 and Wash 2), it might be

285 helpful to increase the repeatability even further. As pointed out by Hartmann and Palzer (2011),

286 one drawback of the ring shear cells is that they are almost closed, which hampers moisture

287 exchange between the powder and the surrounding atmosphere. If the impurities are not

288 homogeneously distributed in the powder, moisture sorption might be heterogeneous at a local

289 level, leading to various degrees of consolidation. It is however interesting to note the low

290 standard deviation associated with the results for Wash 0 and Wash 0.3 . It seems therefore that

291 once humidity caking has reached a certain level, it systematically proceeds to strong and

292 repeatable caking. This level may be associated with the $\mathrm{DRH}$ which, as explained in section

293 3.2., can be significantly decreased by the presence of impurities. Moreover, a critical step in the

294 experimental procedure is relieving the shear cells from the consolidation pressure and moving

295 them from the humidity controlled chamber to the ring shear tester. This operation requires care

296 as interactions between the powder particles can be damaged. It is thus consistent that the

297 stronger the interactions between particles, the better the caking reproducibility.

298 4. Conclusions

299 Time consolidation experiments with a ring shear tester constitute an appropriate method to

300 discriminate between samples with different caking tendencies. Combined with DVS

301 measurements and characterization of the physicochemical composition, including the

302 amorphous content, the caking test results suggested a humidity caking mechanism. The

303 presence of impurities in lactose powder was found to greatly enhance moisture sorption and 
305 to prevent caking in the final product.

306 
This work was partially funded by Innovation Fund Denmark. The authors wish to thank Jens

Kristian Bech for his input in the preparation of the pilot trial and Morten Nielsen for his great

310 help in conducting the trial. We are grateful to Betina Mikkelsen and Anne Dolivet for showing us

311 how to conduct SEM imaging and for all the physicochemical characterization analyses.

\section{References}

313 Bronlund, J., 1997. The modelling of caking in bulk lactose. Massey University.

314 Bronlund, J., Paterson, T., 2004. Moisture sorption isotherms for crystalline, amorphous and predominantly crystalline lactose powders. Int. Dairy J. 14, 247-254. doi:10.1016/S09586946(03)00176-6

Buckton, G., Darcy, P., 1995. The use of gravimetric studies to assess the degree of crystallinity of predominantly crystalline powders. Int. J. Pharm. 123, 265-271.

Carpin, M., Bertelsen, H., Bech, J.K., Jeantet, R., Risbo, J., Schuck, P., 2016. Caking of lactose: A critical review. Trends Food Sci. Technol. 53, 1-12. doi:10.1016/j.tifs.2016.04.002

Giron, D., Monnier, S., Mutz, M., Piechon, P., Buser, T., Stowasser, F., Schulze, K., Bellus, M., 2007. Comparison of quantitative methods for analysis of polyphasic pharmaceuticals. J. Therm. Anal. Calorim. 89, 729-743. doi:10.1007/s10973-006-7962-y

327 Gustafsson, C., Lennholm, H., Iversen, T., Nystro, C., 1998. Comparison of solid-state NMR and isothermal microcalorimetry in the assessment of the amorphous component of lactose. Int. J. Pharm. 174, 243-252.

Guu, M.Y.K., Zall, R.R., 1991. Lactose Crystallization - Effects of Minerals and Seeding. Process Biochem. 26, 167-172. doi:10.1016/0032-9592(91)80013-F

Guu, Y.K., Zall, R.R., 1992. Nanofiltration Concentration Effect on the Efficacy of Lactose Crystallization. J. Food Sci. 57, 735-739. doi:10.1111/j.1365-2621.1992.tb08084.x and applications. Powder Technol. 206, 112-121. doi:10.1016/j.powtec.2010.04.014 
Hourigan, J., Lifran, E., Vu, L., Listiohadi, Y., Sleigh, R, 2013. Lactose: Chemistry, Processing,

and Utilization, in: Smithers, G.W., Augustin, M.A. (Eds.), Advances in Dairy Ingredients. John Wiley \& Sons, Inc., pp. 31-69.

International Dairy Federation, 2015. The world dairy situation 2015, Bulletin of the International

Jenike, A.W., 1964. Storage and flow of solids, Bulletin 123 of the University of Utah. Salt Lake Isengard, H.D., 2001. Water content, one of the most important properties of food. Food Control Dairy Federation 481/2015. doi:10.1111/j.1471-0307.2010.00573.x City.

Jouppila, K., Roos, Y.H., 1994. Glass Transitions and Crystallization in Milk Powders. J. Dairy Sci. 77, 2907-2915. doi:10.3168/jds.S0022-0302(94)77231-3

Listiohadi, Y., Hourigan, J., Sleigh, R., Steele, R., 2008. Moisture sorption, compressibility and caking of lactose polymorphs. Int. J. Pharm. 359, 123-34. doi:10.1016/j.ijpharm.2008.03.044

Listiohadi, Y., Hourigan, J., Sleigh, R., Steele, R., 2005a. Role of amorphous lactose in the caking of $\alpha$-lactose monohydrate powders. Aust. J. dairy Technol. 60, 19-32.

Listiohadi, Y., Hourigan, J., Sleigh, R., Steele, R., 2005b. Effect of milling on the caking behaviour of lactose. Aust. J. Dairy Technol. 60, 214-224.

Mathlouthi, M., Rogé, B., 2003. Water vapour sorption isotherms and the caking of food powders. Food Chem. 82, 61-71. doi:10.1016/S0308-8146(02)00534-4

Paterson, A.H.J., 2009. Production and uses of lactose, in: McSweeney, P.L.H., Fox, P.F. (Eds.), Advanced Dairy Chemistry. Springer New York, pp. 105-120. doi:10.1007/978-0$387-84865-5$

Paterson, A.H.J., Bronlund, J.E., 2009. The practical implications of temperature induced moisture migration in bulk lactose. J. Food Eng. 91, 85-90. doi:10.1016/j.jfoodeng.2008.08.021

Salameh, A.K.A., Mauer, L.J.L., Taylor, L.S.L., 2006. Deliquescence Lowering in Food Ingredient Mixtures. J. Food Sci. 71, E10-E16. doi:10.1111/j.1365-2621.2006.tb12392.x

364 Schuck, P., Dolivet, A., Jeantet, R., 2012. Analytical Methods for Food and Dairy Powders. 
Schulze, D., 2008. Powders and Bulk Solids: Behavior, Characterization, Storage and Flow. Springer Berlin Heidelberg, Berlin, Heidelberg. doi:10.1007/978-3-540-73768-1

Sheokand, S., Modi, S.R., Bansal, A.K., 2014. Dynamic Vapor Sorption as a Tool for Characterization and Quantification of Amorphous Content in Predominantly Crystalline

371 Stoklosa, A.M., Lipasek, R. a., Taylor, L.S., Mauer, L.J., 2012. Effects of storage conditions, formulation, and particle size on moisture sorption and flowability of powders: A study of deliquescent ingredient blends. Food Res. Int. 49, 783-791. doi:10.1016/j.foodres.2012.09.034

Tereshchenko, A.G., 2015. Deliquescence: Hygroscopicity of Water-Soluble Crystalline Solids. J. Pharm. Sci. doi:10.1002/jps.24589

Thomsen, M.K., Jespersen, L., Sjostrom, K., Risbo, J., Skibsted, L.H., 2005. Water activitytemperature state diagram of amorphous lactose. J. Agric. Food Chem. 53, 9182-9185. doi:10.1021/jf0508394

Vollenbroek, J., Hebbink, G. a., Ziffels, S., Steckel, H., 2010. Determination of low levels of 383 
Table 1: Composition of lactose powders as a function of degree of washing of the crystals. Results are given as average \pm standard deviation. Number of repeats $=3$ for moisture and ash and 2 for proteins.

Figure 1: Variations in the mineral content (potassium (K), chlorine (Cl), sodium (Na), phosphorus $(P)$, calcium $(\mathrm{Ca})$, and magnesium $(\mathrm{Mg})$ ) of lactose powder as a function of degree of washing of the lactose crystals.

Figure 2: Particle size distributions of lactose powders for three different washing grades $(0,1,2)$ but with the same particle size fraction $(160<x<250 \mu \mathrm{m})$.

Figure 3: Moisture sorption isotherms of lactose powders with three different washing grades but the same particle size fraction $(160<x<250 \mu \mathrm{m})$ : Wash 0 (squares), Wash 1 (circles), Wash 2 (triangles).

Figure 4: Moisture sorption isotherms of non-sieved pharmaceutical grade lactose (circles) and the most washed lactose from the pilot trial (Wash 2) (squares).

Figure 5: SEM images showing details of particle surface of different washing grade lactose powders: (A) Wash 0; (B) Wash 0.5; (C) Wash 1; (D) Wash 2; (E) Pharmaceutical grade lactose.

Figure 6: $13 C$ CP/MAS NMR spectra of $(A)$ Wash 0; (B) Wash 0.3; (C) pharmaceutical grade lactose; (D) amorphous lactose.

Figure 7: ffc of non-sieved (crosses) and sieved (triangles) lactose powders between $160 \mu \mathrm{m}$ and $250 \mu \mathrm{m}$ as a function of the washing grade. The ffc was measured after storage for four days at $60 \% \mathrm{RH}$ and $20 \mathrm{C}$. Each sam ple was consolidated under a pressure of $9.3 \mathrm{kPa}$. The flowability of pharmaceutical grade lactose after storage is included for comparison purposes. 
Table 1: Composition of lactose powders as a function of degree of washing of the crystals.

Results are given as average \pm standard deviation. Number of repeats $=3$ for moisture and ash and 2 for proteins.

\begin{tabular}{lllll}
\hline Washing Grade & Protein $\left(\mathrm{g} .100 \mathrm{~g}^{-1}\right)$ & Moisture $\left(\mathrm{g} .100 \mathrm{~g}^{-1}\right)$ & Ash $\left(\mathrm{g} .100 \mathrm{~g}^{-1}\right)$ & Lactose $\left(\mathrm{g} .100 \mathrm{~g}^{-1}\right)$ \\
\hline 0 & $0.640 \pm 0.014$ & $1.12 \pm 0.01$ & $2.14 \pm 0.05$ & 96.09 \\
0.3 & $0.332 \pm 0.005$ & $0.89 \pm 0.00$ & $0.79 \pm 0.04$ & 97.99 \\
0.5 & $0.227 \pm 0.006$ & $0.77 \pm 0.02$ & $0.52 \pm 0.02$ & 98.49 \\
1 & $0.152 \pm 0.006$ & $0.36 \pm 0.02$ & $0.43 \pm 0.04$ & 99.05 \\
2 & $0.082 \pm 0.001$ & $0.31 \pm 0.01$ & $0.19 \pm 0.00$ & 99.42 \\
\hline $\begin{array}{l}\text { Pharmaceutical } \\
\text { grade lactose }\end{array}$ & $0.004 \pm 0.002$ & n.d. & $0.01 \pm 0.00$ & n.d. \\
\hline
\end{tabular}




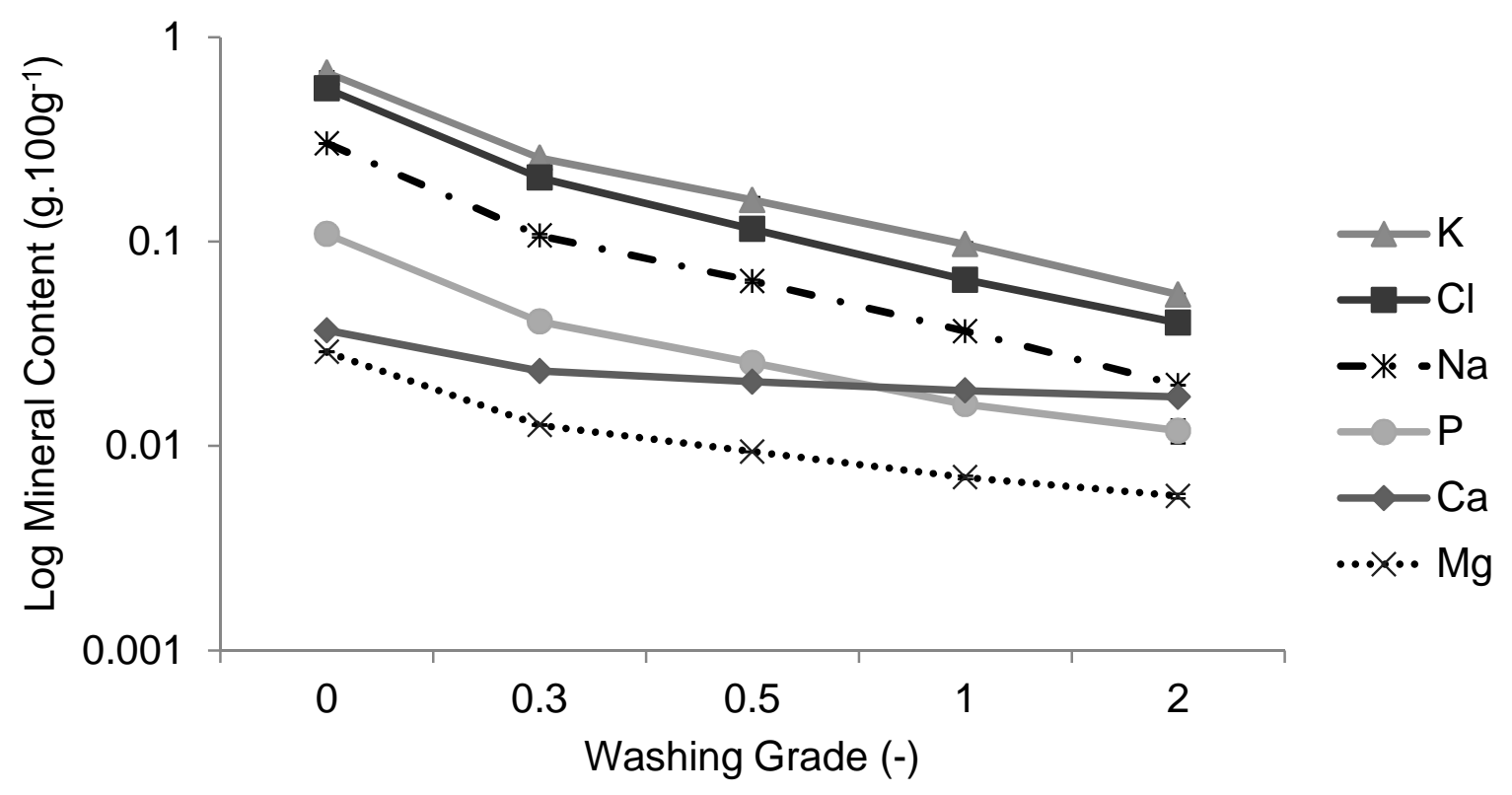

Figure 1: Variations in the mineral content (potassium (K), chlorine (Cl), sodium (Na), phosphorus $(P)$, calcium (Ca), and magnesium $(\mathrm{Mg})$ ) of lactose powder as a function of degree of washing of the lactose crystals. 


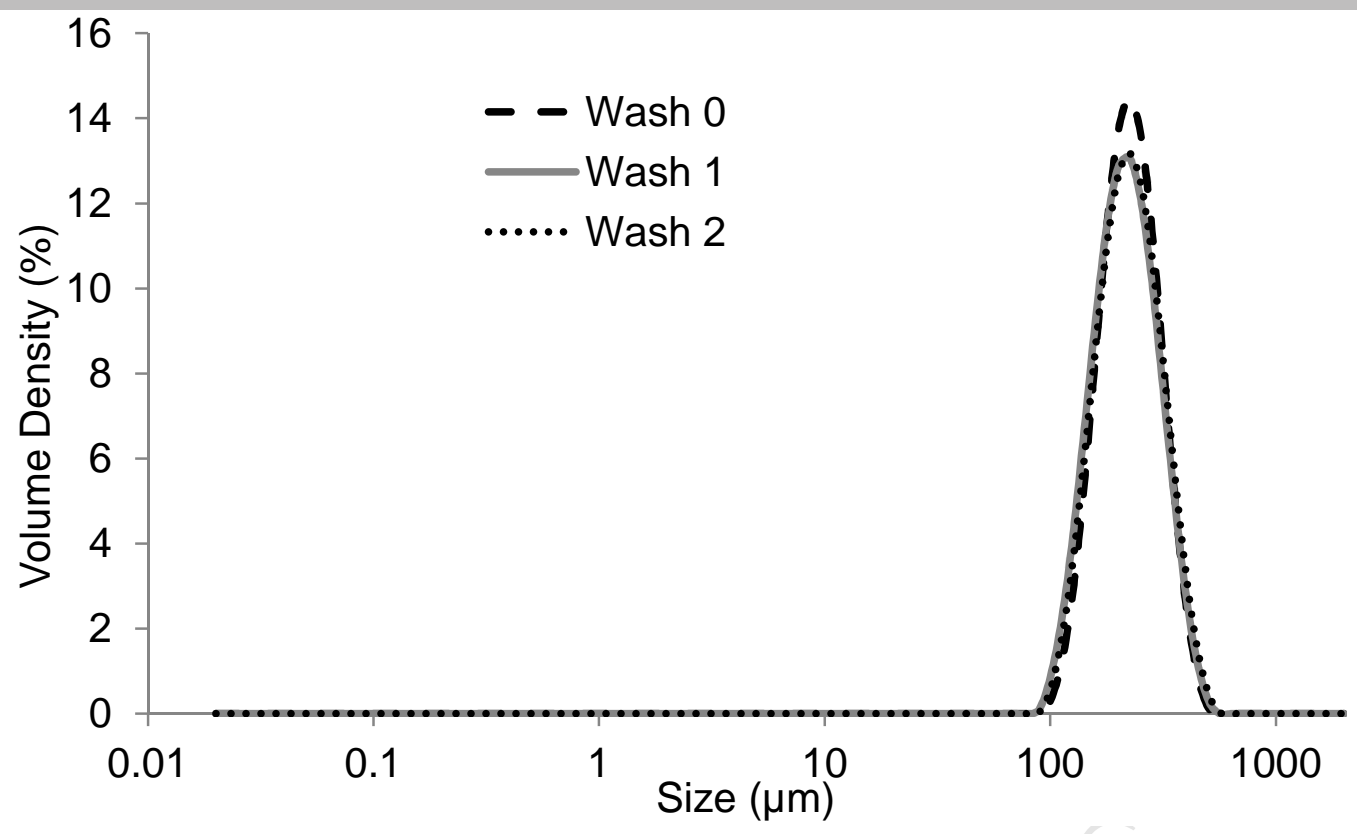

Figure 2: Particle size distributions of lactose powders for three different washing grades $(0,1,2)$ but with the same particle size fraction $(160<x<250 \mu \mathrm{m})$. 


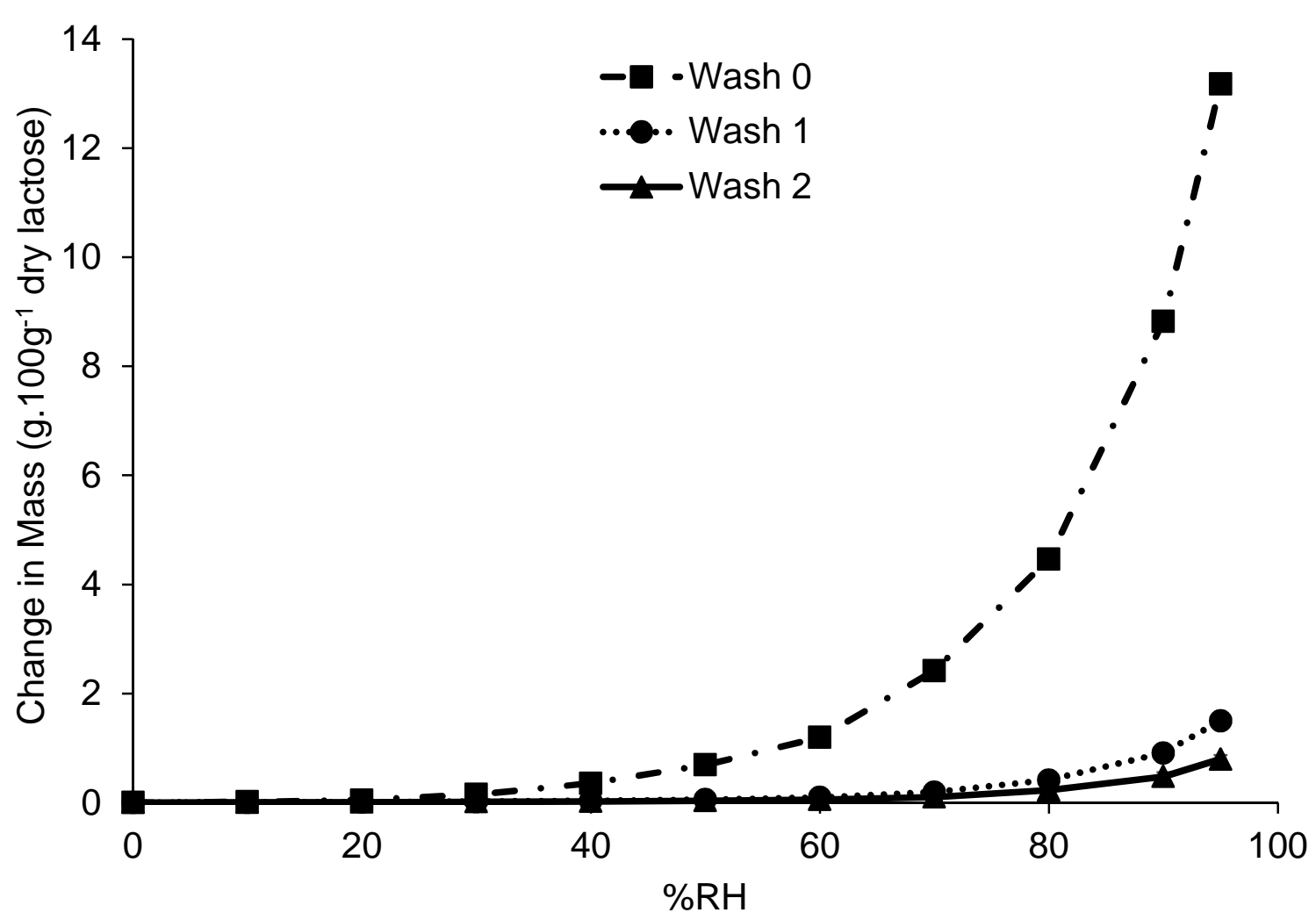

Figure 3: Moisture sorption isotherms of lactose powders with three different washing grades but the same particle size fraction $(160<x<250 \mu \mathrm{m})$ : Wash 0 (squares), Wash 1 (circles), Wash 2 (triangles). 


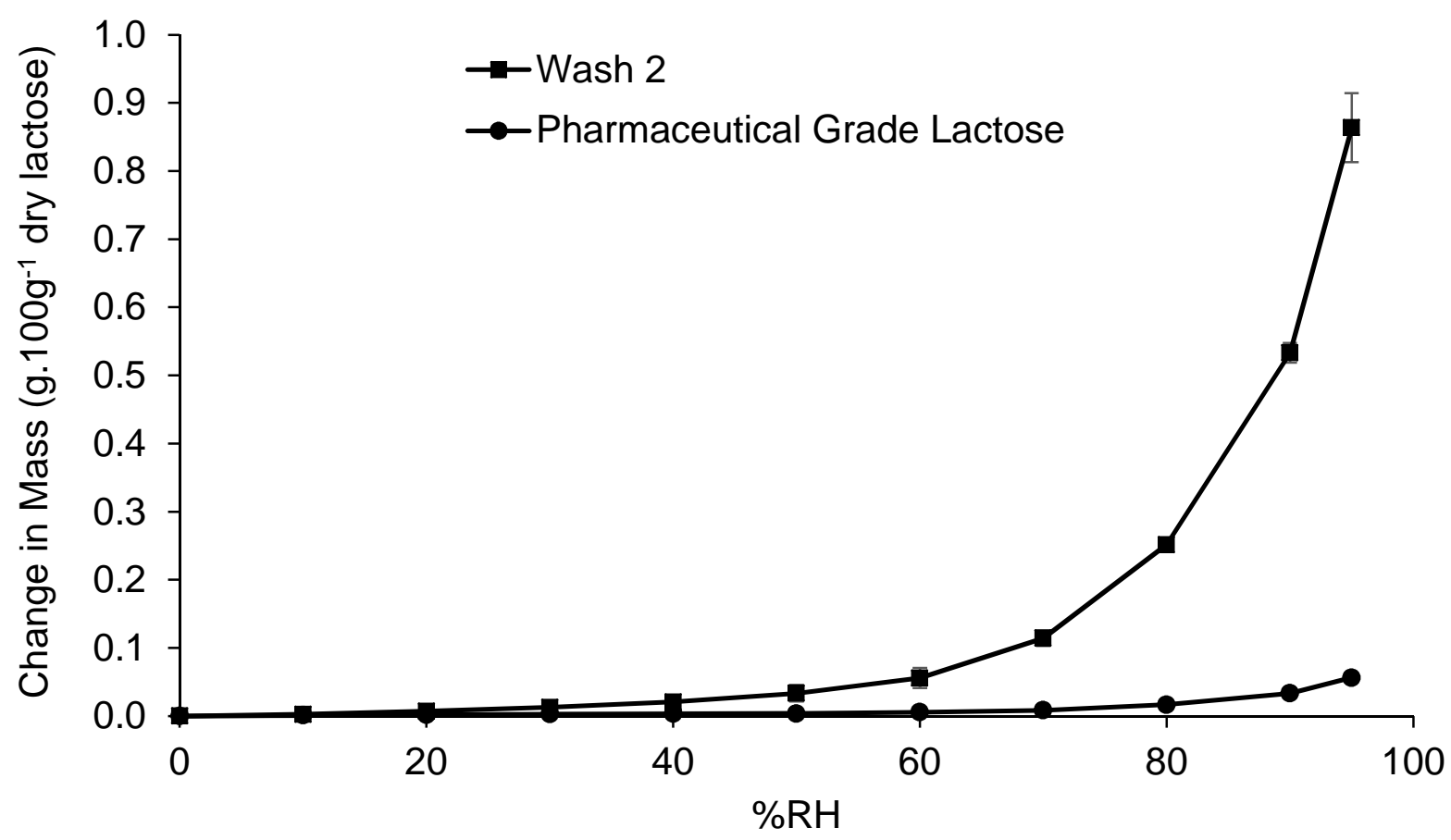

Figure 4: Moisture sorption isotherms of non-sieved pharmaceutical grade lactose (circles) and the most washed lactose from the pilot trial (Wash 2) (squares). 

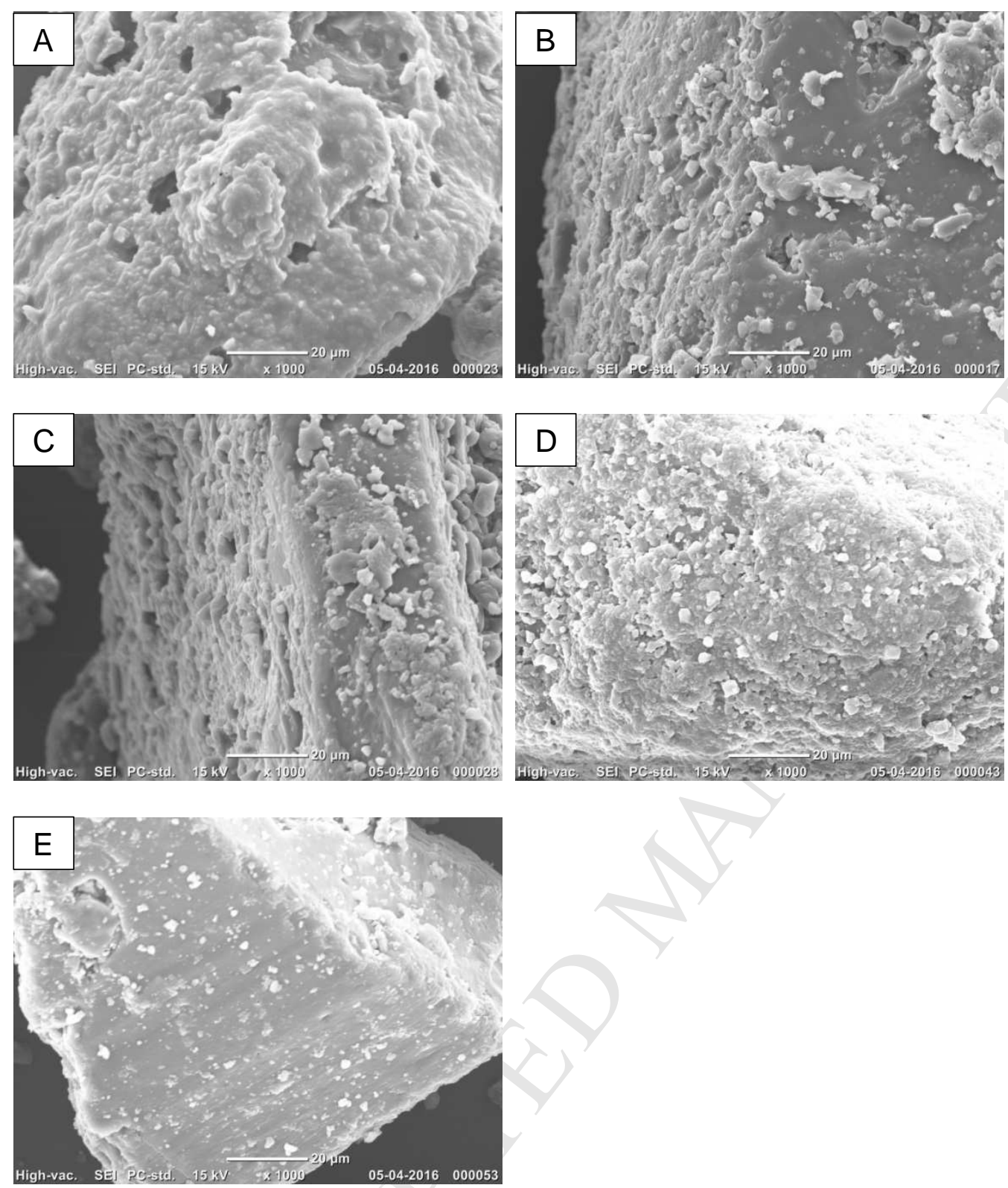

Figure 5: SEM images showing details of particle surface of different washing grade lactose powders: (A) Wash 0; (B) Wash 0.5; (C) Wash 1; (D) Wash 2; (E) Pharmaceutical grade lactose. 


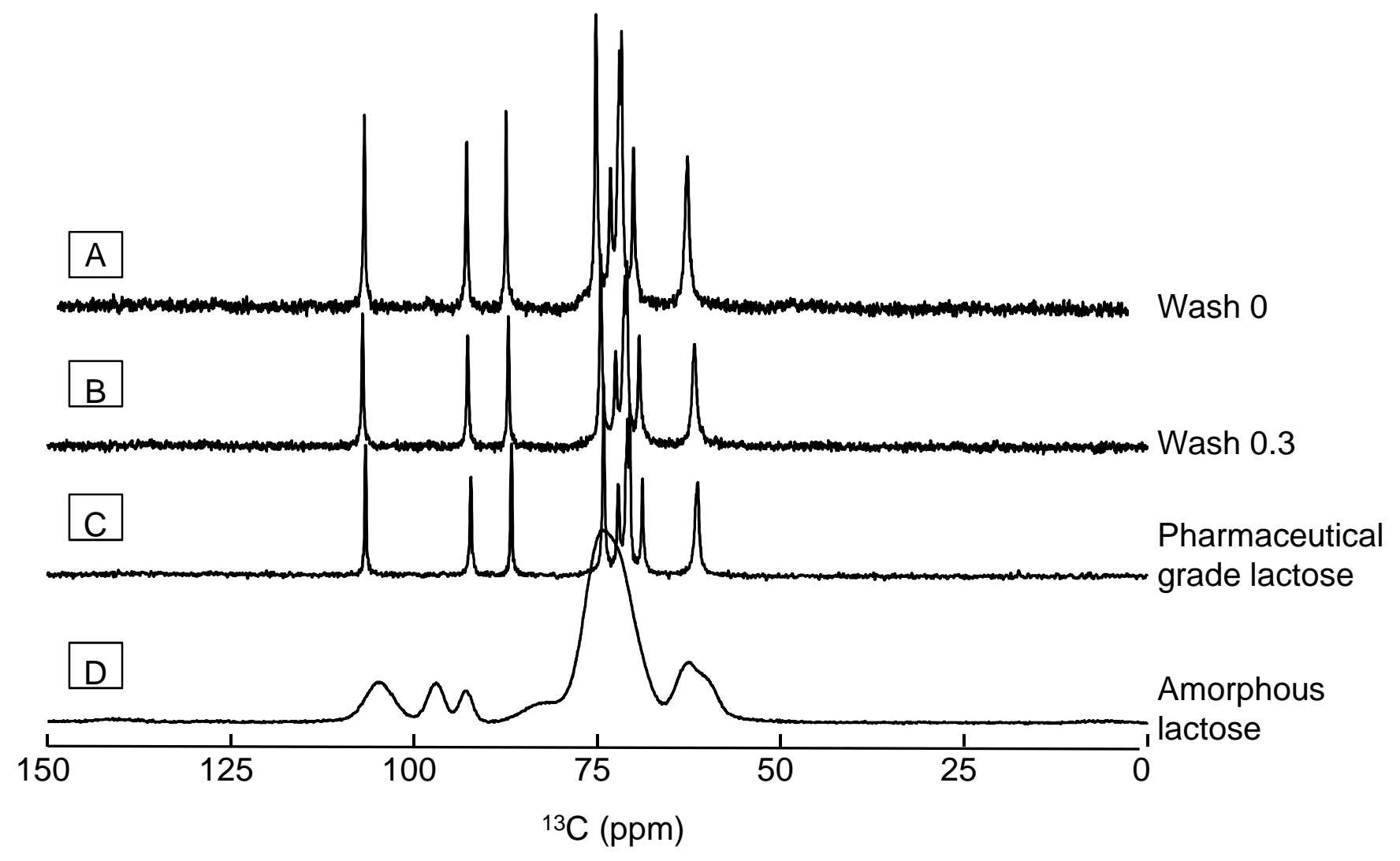

Figure 6: 13C CP/MAS NMR spectra of (A) Wash 0; (B) Wash 0.3; (C) pharmaceutical grade lactose; (D) amorphous lactose. 


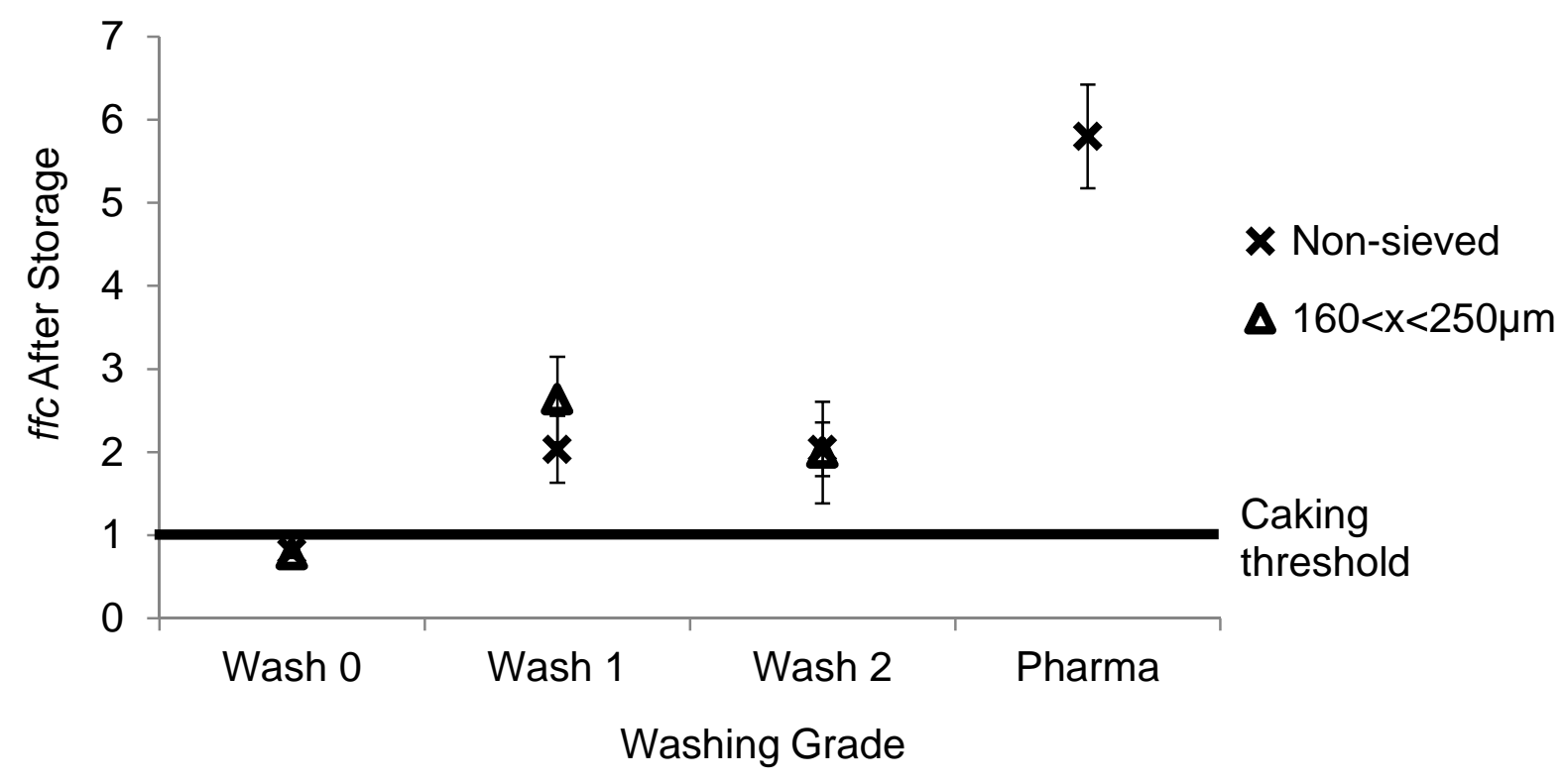

Figure 7: ffc of non-sieved (crosses) and sieved (triangles) lactose powders between $160 \mu \mathrm{m}$ and $250 \mu \mathrm{m}$ as a function of the washing grade. The ffc was measured after storage for four days at $60 \% \mathrm{RH}$ and $20 \mathrm{C}$. Each sample was consolida ted under a pressure of $9.3 \mathrm{kPa}$. The flowability of pharmaceutical grade lactose after storage is included for comparison purposes. 
- Caking of lactose results in non-conform products and significant economic loss.

- Impurities in the lactose powder increased moisture sorption and caking tendency.

- The ring shear tester is a valuable tool to assess caking.

- The washing and purification steps should be closely monitored to limit caking. 